\title{
The Variability and Evaluation Method of Recycled Concrete Aggregate Properties
}

\author{
Zhiqing Zhang, ${ }^{1}$ Bozhao Shen, ${ }^{2}$ Hui Ren, ${ }^{3}$ Jin Wang, ${ }^{2}$ Shiyun Li, ${ }^{2}$ and Hao Liu ${ }^{2}$ \\ ${ }^{1}$ Engineering Research Center of Urban Transportation, Beijing University of Technology, No. 100 Pin Le Yuan, \\ Chaoyang District, Beijing 100124, China \\ ${ }^{2}$ College of Metropolitan Transportation, Beijing University of Technology, No. 100 Pin Le Yuan, Chaoyang District, \\ Beijing 100124, China \\ ${ }^{3}$ College of Engineering and Applied Science, University of Cincinnati, Cincinnati, OH 45221, USA
}

Correspondence should be addressed to Zhiqing Zhang; zhangzhiqing@bjut.edu.cn

Received 14 April 2017; Revised 9 July 2017; Accepted 12 September 2017; Published 23 October 2017

Academic Editor: Hainian Wang

Copyright (C) 2017 Zhiqing Zhang et al. This is an open access article distributed under the Creative Commons Attribution License, which permits unrestricted use, distribution, and reproduction in any medium, provided the original work is properly cited.

\begin{abstract}
With the same sources and regeneration techniques, given RA's properties may display large variations. The same single property index of different sets maybe has a large difference of the whole property. How shall we accurately evaluate the whole property of RA? 8 groups of RAs from pavement and building were used to research the method of evaluating the holistic characteristics of RA. After testing and investigating, the parameters of aggregates were analyzed. The data of physical and mechanical properties show a distinct dispersion and instability; thus, it has been difficult to express the whole characteristics in any single property parameter. The Euclidean distance can express the similarity of samples. The closer the distance, the more similar the property. The standard variance of the whole property Euclidean distances for two types of RA is $S_{k}=7.341$ and $S_{k}=2.208$, respectively, which shows that the property of building RA has great fluctuation, while pavement RA is more stable. There are certain correlations among the apparent density, water absorption, and crushed value of RAs, and the Mahalanobis distance method can directly evaluate the whole property by using its parameters: mean, variance, and covariance, and it can provide a grade evaluation model for RAs.
\end{abstract}

\section{Introduction}

Accurate evaluation of RA is beneficial to its rational utilization. The current problems in evaluating the variability of RA are focused on the application of RA mixture only, regardless of the study and conclusion [1]. How shall we accurately express the whole property of RA and how shall we effectively evaluate the grade of RA? So far, there is still no reasonable method to be seen, and most of the evaluation methods are the evaluation of mixtures with RAs.

The single properties of aggregates are usually described by the apparent relative density, water absorption, crushed value, wear value, the adhesion index, while the comprehensive property is the whole property of aggregate showed in applications. The single property of different RAs shows a large variability, so the comprehensive evaluation method of each kind of RA needs to be studied.
Over the past decades, the United States, Europe, and other developed countries have promulgated some quality standards and technical specifications of RA according to the RA characteristics of their own countries. Although each of them has their own characteristic, it is still insufficient for the evaluation method. The main problem is that they focused more on the single property index and neglected the whole property evaluation for the RA [2-4]. For example, the American Society for Testing and Materials (ASTM) made clear provisions for the extremum of the evaluation index of coarse aggregate in different engineering fields. The British Standard (BS) divided RA into three grades based on different sources $[3,5]$. V. W. Y. Tam and C. M. Tam further put forward the RA should be divided into 7 grades in view of the evaluation indices of apparent relative density, water absorption, flakiness content, impact value, the contents of chloride, and sulfate in 2007 [6]. The common problem is that the grading standard is too absolute and does 
TABLE 1: Properties of RA and NA.

\begin{tabular}{|c|c|c|c|c|c|}
\hline Type of aggregate & Density $\left(\mathrm{g} / \mathrm{cm}^{3}\right)$ & Water absorption (\%) & Crushing value (\%) & Abrasion value (\%) & Adhesion grade \\
\hline \multicolumn{6}{|l|}{ RA } \\
\hline $\mathrm{RA}_{1}(4.75-9.50 \mathrm{~mm})$ & 2.730 & 2.171 & 13.32 & 13.60 & 2 \\
\hline $\mathrm{RA}_{2}(4.75-13.2 \mathrm{~mm})$ & 2.742 & 2.233 & 13.40 & 13.60 & 3 \\
\hline $\mathrm{RA}_{3}(9.50-19.0 \mathrm{~mm})$ & 2.780 & 1.695 & 13.58 & 15.00 & 4 \\
\hline \multicolumn{6}{|l|}{ NA } \\
\hline $\mathrm{NA}_{1}(4.75-9.50 \mathrm{~mm})$ & 2.751 & 0.802 & 18.82 & 23.55 & 5 \\
\hline $\mathrm{NA}_{2}(4.75-13.2 \mathrm{~mm})$ & 2.793 & 0.798 & 19.01 & 23.55 & 5 \\
\hline $\mathrm{NA}_{3}(9.50-19.0 \mathrm{~mm})$ & 2.842 & 0.755 & 20.68 & 22.65 & 5 \\
\hline Commonly acceptable & $\geq 2.600$ & $\leq 2.000$ & $\leq 28.00$ & $\leq 30.00$ & $\geq 4$ \\
\hline
\end{tabular}

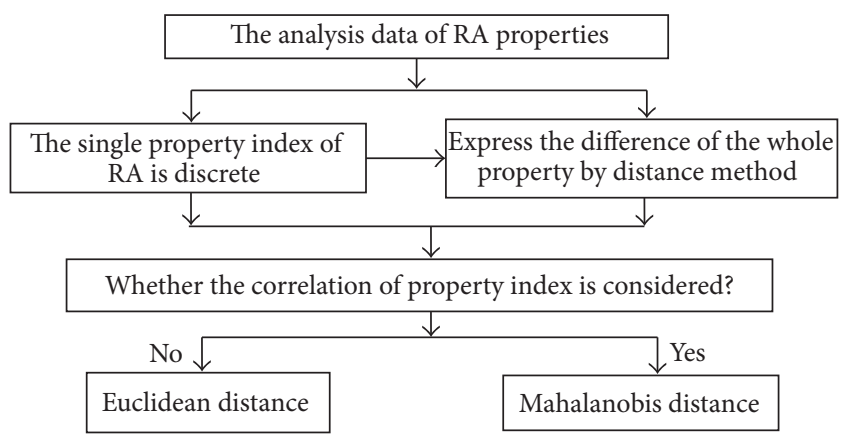

FIGURE 1: RA property evaluation flow chart.

not give the whole characteristics requirement in different application fields. In 1998 Germany promulgated "Regeneration Aggregate Concrete Application Guide," where the quality requirements of RA must comply with the technical requirements of natural aggregate (NA) [7,8]. It ignores the characteristics of RA, and it is not conducive to the application of concrete aggregate. Although Spain and other countries have not given a clear classification and grading standard of the RA, only relevant qualification was performed with recycled coarse aggregate $[9,10]$. The standard did not include many details. The common features are that these specifications only gave a different range of values for a single property index of the RA and did not make provisions for the whole properties.

Because of the complexity of RA sources and regeneration techniques, an RA's properties show large variations in its microstructure and physical, mechanical, and chemical properties [1]. The test values show a large variability; the same single property index of different sets maybe has a large difference of the whole property, so the whole property of RA could not be only expressed by a single property index. Adopting the Euclidean distance method and Mahalanobis distance method, respectively, in evaluating the single and whole property of RA is proposed in this paper. The flow chart is demonstrated in Figure 1.

\section{Test and Analysis of the Characteristic of RA Used}

2.1. Aggregate Characteristic Test. Two types of aggregates were used in the present study: (1) RA produced from the old building foundation concrete on the twentieth century, 1980s. Its strength was equivalent to C20, and the coarse aggregate was comprised of pebbles. The production process stages of RA were pretreatment, crushing, grinding, screening, and washing. (2) NA is made from granite.

The RAs used in the present study were screened into three different sizes $(4.75-9.50 \mathrm{~mm}, 4.75-13.2 \mathrm{~mm}$, and 9.50-19.0 mm) with the same processing method. After sampling, the aggregates were sieved with $4.75 \mathrm{~mm}$ standard sieve and then rinsed with water to ensure that they are free of dirt and dust (see Figure 2) [11].

The properties of the RA and NA, such as apparent relative density, water absorption, crushed value, wear value, and the adhesion, were tested according to the Chinese standard. Table 1 presents the results from the above-described tests.

As indicated in Table 1, the properties of NA tested satisfy all commonly acceptance, while RAs had higher water absorption and lower adhesion to asphalt values than the listed, commonly accepted values.

2.2. Aggregate Characteristic Analysis. As shown in Table 1, the apparent relative densities of RA with different particle sizes are similar, and they are all slightly lower than those of NA. In addition, the water absorption of RA is much higher than that of NA for the same size of aggregate. These may be mainly attributed to the high porosity, or low density, of the mortar adhered on the surface of the aggregate. In addition, during the production process of RA, mechanical crushing, particle collision, and sliding also produce microcracks in the aggregate, and these will result in an increase in the aggregate porosity and a decrease in the apparent relative density. The porous mortar and fine cracks are also responsible for the high water absorption of the RAs. Furthermore, the high silt content on the surface of the RA particles may also help to increase the rate and amount of water absorption.

The crush values of RAs are clearly lower than those of NA. And the degree of abrasion of RAs is all lower than that of NA. A main reason for these is that the RAs had already gone through a crushing process during recycling. After crushing, washing, and sieving, the RAs had high pebble content with good integrity. As a result, the RAs used in this study had a higher crushing and abrasion resistance than the NA. This suggests that the lower the strength of the original concrete, the smaller the damage degree in the process of the aggregate regeneration and the better the property of resistance to crushing of the recycled aggregate. 


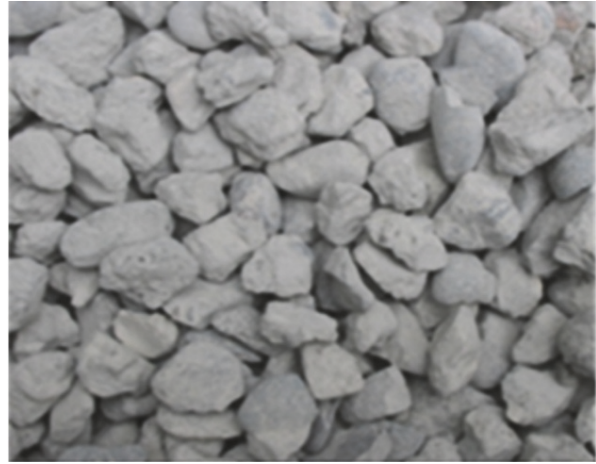

(a) $\mathrm{RA}$ as received

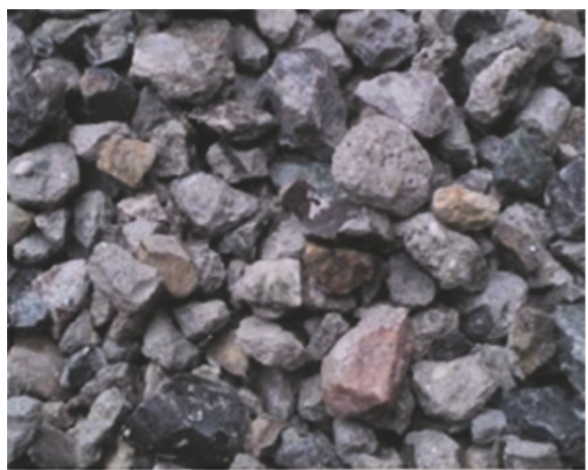

(b) RA after cleaning and sieving

Figure 2: RA before and after washing.

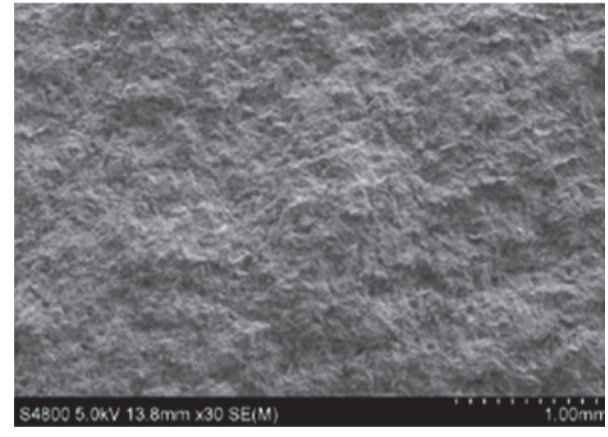

(a) NA 30-time SEM picture

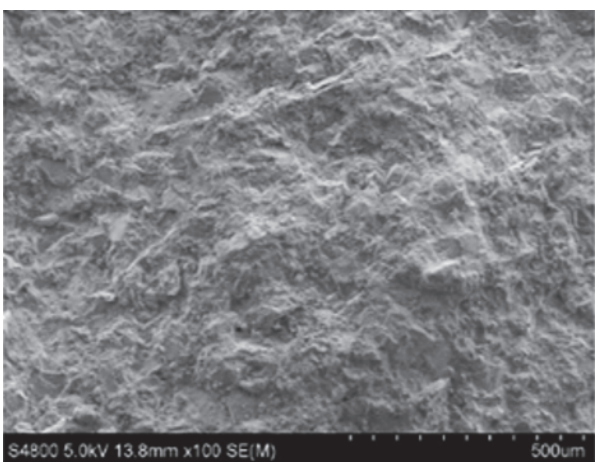

(c) NA 100-time SEM picture

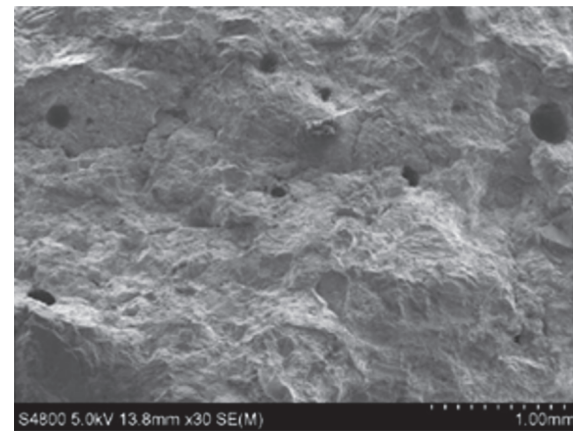

(b) RA 30-time SEM picture

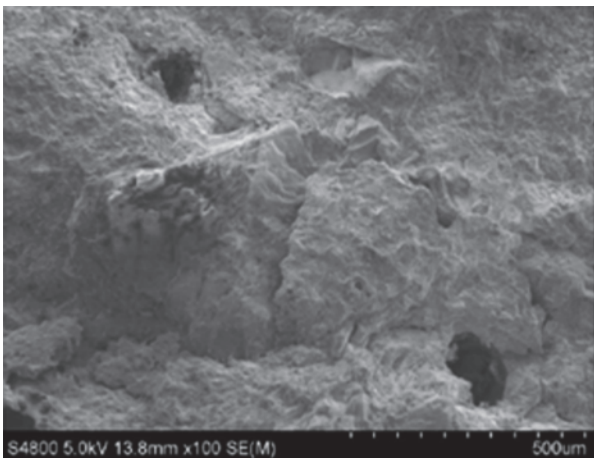

(d) RA 100-time SEM picture

FIGURE 3: RA/NA SEM pictures.

Adhesion of aggregate to asphalt is critical for the property of asphalt concrete pavements. Table 1 shows that among three RA samples tested, two had adhesion level values less than 4 as required. It was observed during the adhesion testing that the general peeling area was around $10 \%$, and localized peeling area summed up to $30 \%$. The weak adhesion of RA may be related to the reaction of water soluble ions leaching out from the adhered mortar on the aggregate surface with the carboxylic acids of asphalts.

A scanning electron microscope (SEM) was used to observe the microstructure of RA and NA, as shown in Figure 3.
It can be seen that RA possesses a large number of pores and microcracks internally caused by the accumulated damage during crushing, leading to an increase in the void ratio, water absorption, and crush value (shown in Figure 3). Compared to the surface structure of NA, the asphalt bonding material can penetrate into the RA surface more easily. Further, the strength of interface may be improved.

In summary, for the RA from low strength concrete, except for the water absorption rate, the other properties of RA appear better than that of NA. Perhaps this is a special case; more extensive investigation may need to be done. 
TABLE 2: Property data of RA from buildings.

\begin{tabular}{lcccccccc}
\hline Property index & $A$ & $B$ & $C$ & $D$ & $E$ & $F$ & $G$ \\
\hline Density $\left(\mathrm{g} / \mathrm{cm}^{3}\right)$ & 2.742 & 2.529 & 2.5 & 2.535 & 2.75 & 2.32 & 2.265 & 2.658 \\
Absorption (\%) & 1.94 & 4.82 & 2.15 & 4.50 & 2.49 & 9.89 & 5.70 & 4.50 \\
Flakiness (\%) & 6.98 & 3.70 & 2.50 & 3.40 & 3.00 & 2.50 & 3.10 & 2.60 \\
Crushing value (\%) & 13.60 & 13.80 & 14.10 & 7.87 & 6.20 & 24.20 & 30.00 & 13.00 \\
Stone species & Pebbles & Pebbles & Pebbles & Pebbles & Gravel & Gravel & Gravel & Gravel \\
Strength & Low & Low & Low & Low & Low & Low & Low & Low \\
Sources & Foundation & Floor & Building & Beam & Foundation & Building & Building & Building \\
\hline
\end{tabular}

TABle 3: Property data of RA from pavement.

\begin{tabular}{lcccccccc}
\hline Property index & $a$ & $b$ & $c$ & $d$ & $e$ & $f$ & $g$ \\
\hline Density $\left(\mathrm{g} / \mathrm{cm}^{3}\right)$ & 2.67 & 2.64 & 2.64 & 2.68 & 2.55 & 2.443 & 2.582 & 2.51 \\
Absorption (\%) & 2.50 & 4.20 & 4.20 & 2.50 & 5.7 & 6.00 & 4.00 & 5.70 \\
Flakiness (\%) & 5.20 & 4.60 & 4.00 & 5.10 & 2.37 & 6.30 & 2.90 & 3,30 \\
Crushing value (\%) & 11.10 & 12.00 & 11.50 & 10.90 & 14.20 & 12.60 & 13.30 & 17.20 \\
Stone species & Pebbles & Pebbles & Pebbles & Pebbles & Pebbles & Pebbles & Pebbles & Pebbles \\
Strength & Low & Low & Low & Low & Low & Low & Unknown & Low \\
Sources & Overpass & Pavement & Pavement & Pavement & Pavement & Pavement & Pavement & Pavement \\
\hline
\end{tabular}

\section{Variability Analysis of the RA Property}

3.1. Property Data of RA Tested and Investigated. RA properties can be evaluated by some experimental indices, which include property density, water absorption, needle and flakiness content, and crushing value [12-14].

Sixteen groups of RAs were selected from pavements and buildings, respectively $[15,16]$. Most of the property data were investigated except for groups $E, F$, and NAs, which were tested by ourselves in the laboratory. All of the RAs were crushed by the jaw-crush method (see Tables 2 and 3).

As shown in Tables 2 and 3, the basic property data of the NA are generally property density at $2.63 \mathrm{~g} / \mathrm{cm}^{3}$; water absorption at $1.6 \%$; needle and flakiness content at $5.2 \%$; and crushing value at $9.6 \%$.

3.2. Variability Analysis of the NA Property Data. As can be seen from Tables 1 and 2, there is a little distinction in apparent relative density between RA and NA. Most of the RA's apparent relative density is $88 \% \sim 97 \%$ of the NAs, about $2.31-2.61 \mathrm{~kg} / \mathrm{m}^{3}$. The shapes of RA from different sources have a high degree of similarity; some of them are even better than the NA. The shapes of different sources of RA are similar, and for some the quality is better than the NA; the apparent relative density and needle-flakiness content are relatively stable, while the water absorption and crushing values are relatively higher. The water absorption rate of RA is between $2 \% \sim 10 \%$; the highest value even is up to $12 \%$, which is 2 to 7 times that of the NA. The crushing value of RA varies greatly, and its crush resistance ability is significantly lower than the NA, as is shown in Figure 4.

After being crushed, the RA might produce a large number of microcracks on the aggregate surface and the interior between aggregate and adhesive cement mortar.
Besides, the RA would be cracked more easily when being pressed, and it contains a variety of impurities on the surface; therefore, the RA strength would be lower than NA. As a result, the water absorption and crushing value of RA were significantly larger [7, 17], and the experimental data showed a large variability as well. Since the content of impurities and microcrack is influenced by many factors, such as the types of concrete waste, engineering construction, and crushing method, and the RA from building contains more impurities than that from pavement, its variability would be greater.

3.3. Pavement Property with RA. The conclusions of our previous study about RA's instability are as follows [11].

(1) Compared with NA, the RA recycled from low grade concrete had lower apparent relative density, higher water absorption, and poorer adhesion to asphalt but had probably lower crushing and wearing value.

(2) The rutting deformation of the HMA mixes generally increased with the level of RA replacement, but the low temperature cracking resistance test results showed that the failure load, tensile stress, and modulus of the HMA mixes with RA are all significantly higher than those of the mix with NA.

(3) The water stability measured by immersion compression tests showed a similar trend to that measured by freezethaw splitting strength tests. The water stability of the HMA concrete decreased with increasing RA replacement (up to $50 \%)$. When the RA content reached $75 \%$, the water resistance of the HMA concrete increased, rather than decreased further.

Due to instability, a large variability has been indicated by experimental data of RA property index. Therefore, it is inaccurate to illustrate the whole property through a single property index. It is possible that the whole property is better 


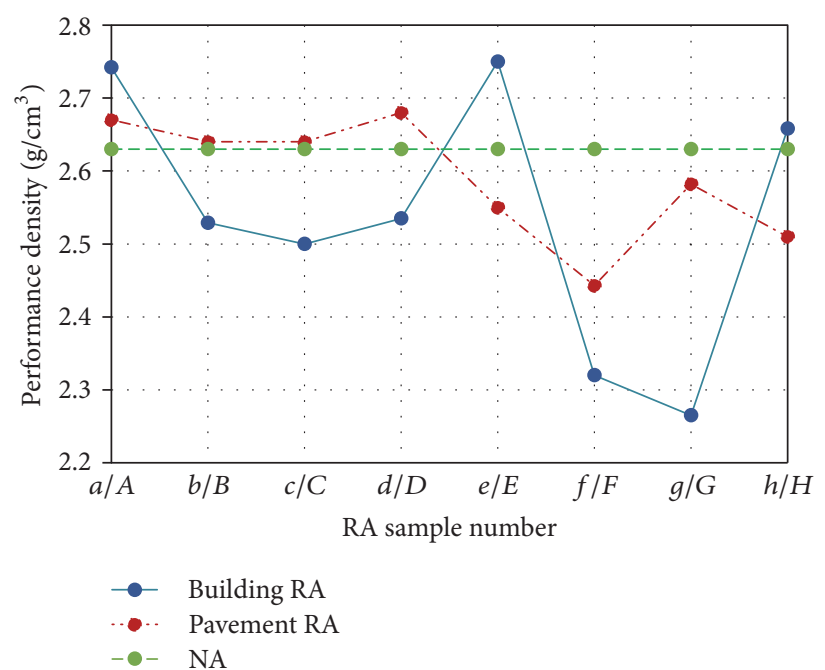

(a) Contrast chart of density of NA and RA

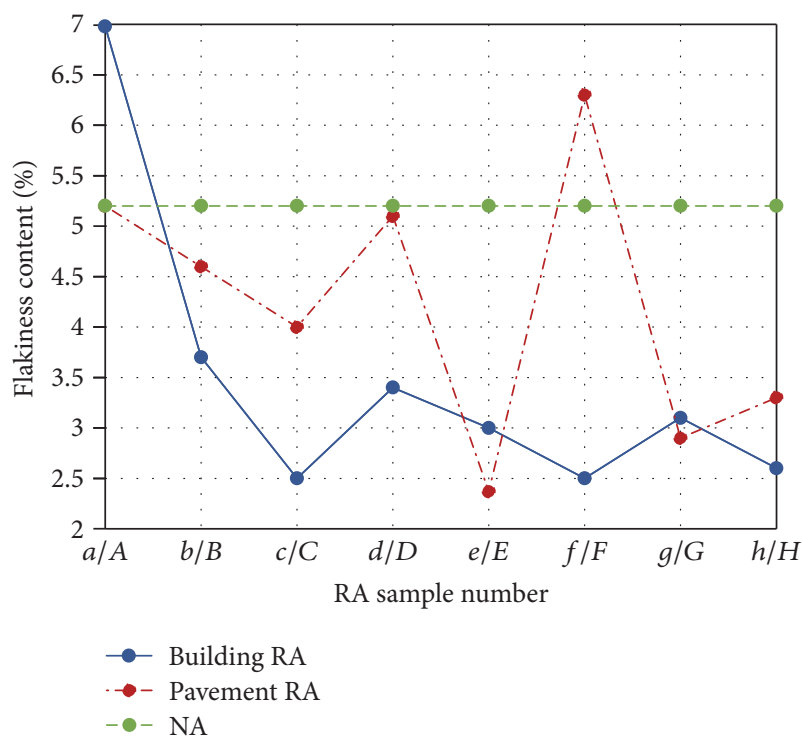

(c) Contrast chart of flakiness of NA and RA

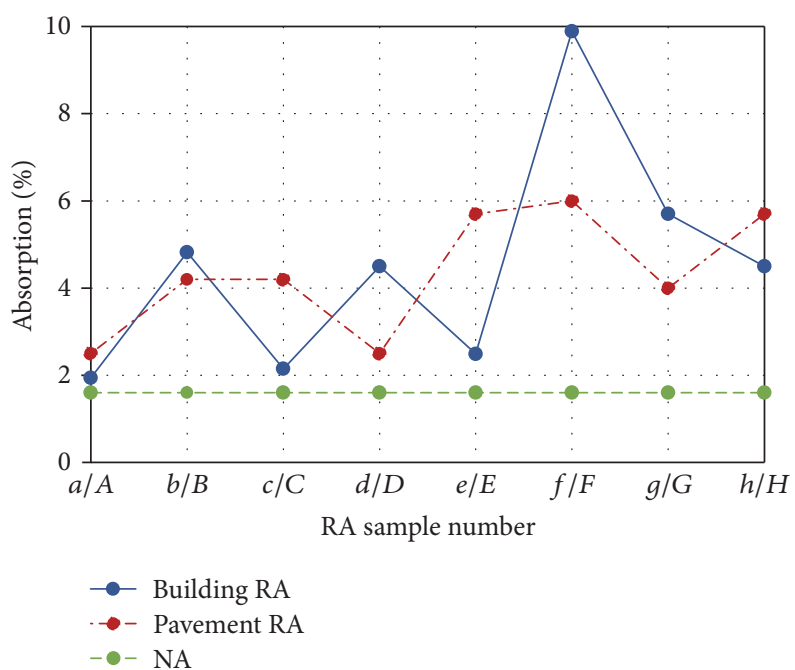

(b) Contrast chart of absorption of NA and RA

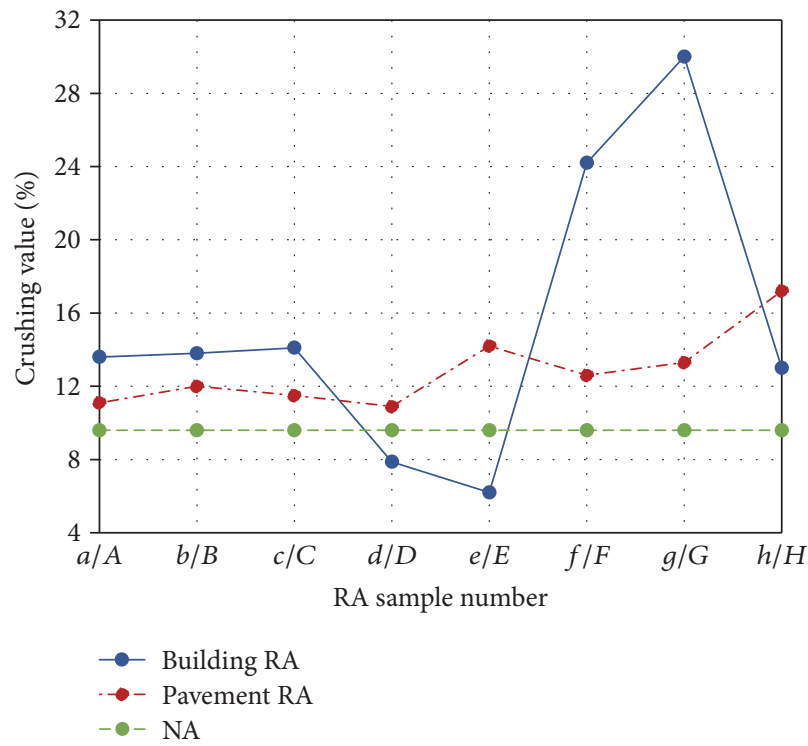

(d) Contrast chart of crushing value of NA and RA

FIGURE 4: Contrast charts of NA and RA properties.

in the asphalt mixture, while a single property index exhibits poor results. However, the distance method is not affected by the dimension and directly expresses the difference of multiple variables or sample set of indices. According to the distance method, it is feasible to illustrate the whole property of RA.

\section{Euclidean Distance Comparison Method of RA}

4.1. Euclidean Distance Calculation of RA Property. (1) The single property Euclidean distance $\rho_{k j}$ is generally

$$
\rho_{k j}=\sqrt{\sum_{i=A / a}^{H / h}\left(x_{j}-y_{k i j}\right)^{2}},
$$

in which $x_{j}$ is property test value of the NA; $y_{k i j}$ is property test values of RA; $k$ is pavement RA or building RA, where $k=$ I (pavement RA) and $k=\mathrm{II}$ (building RA); $i$ is the number of test data groups, when $k=\mathrm{I}, i=A, B, C, D, E, F, G, H$; $k=\mathrm{II}, i=a, b, c, d, e, f, g, h ; j$ is the different property test, $j=1$ (apparent density), 2 (water absorption), 3 (needle and flakiness content), and 4 (crushing value).

(2) The whole property Euclidean distance of RA $\rho_{k i}$ is generally

$$
\rho_{k i}=\sqrt{\sum_{j=1}^{4}\left(x_{j}-y_{k i j}\right)^{2}},
$$

in which $x_{j}, y_{k i j}, k, i$, and $j$ are the same as formulation (1). 
TABLE 4: Euclidean distance of single property of building and pavement RA.

\begin{tabular}{lccr}
\hline Property index & Building RA $(A)$ & Pavement RA $(B)$ & $A-B$ \\
\hline Property density & 0.516 & 0.241 & 0.275 \\
Absorption (\%) & 10.669 & 8.595 & 2.074 \\
Flakiness content (\%) & 1.87 & 0.943 & 0.927 \\
Crushing value (\%) & 26.355 & 10.72 & 15.635 \\
\hline
\end{tabular}

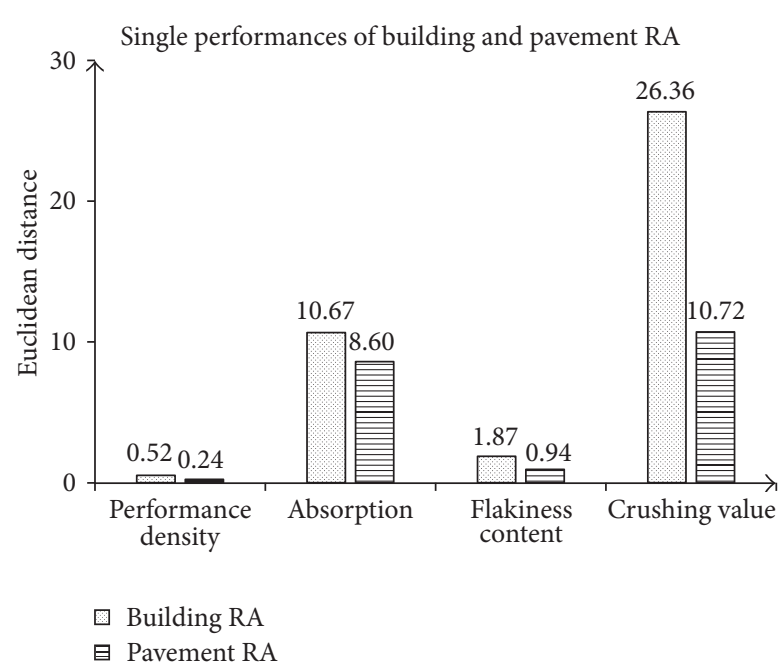

FIGURE 5: Single property of RA.

(3) The whole property Euclidean distance standard variance of RA $S_{k}$ is generally

$$
S_{k}=\sqrt{\frac{\sum_{i=A / a}^{G / g}\left(\rho_{k i}-\bar{\rho}_{k i}\right)^{2}}{7}},
$$

in which type $S_{k}$ is the standard variance of whole property Euclidean distance for building RA and pavement RA; $\bar{\rho}_{k i}$ is the arithmetic mean value of whole property Euclidean distance for the different number of RA; $\rho_{k i}, k$, and $i$ are the same as formulation (1).

\subsection{The Comparison and Analysis of Euclidean Distance of} RA Property. According to the Euclidean distance formula (1)-(3), for the two types of RA, the Euclidean distances of single property and whole property are shown in Tables 4 and 5 and Figures 5 and 6, respectively.

The greater the value of the properties, the greater the difference between the RA and the NA; otherwise, the smaller the value, the closer the difference. The standard variance of the whole property Euclidean distance of building RA and pavement RA was calculated to be 7.341 and 2.208, respectively.

Table 4 and Figure 5 show slightly differences of the property density and flakiness content of RA compared with the NA, while the crushing value and water absorption are obvious differences. In addition, pavement RA was significantly better than building RA in terms of single property index. As shown in Table 5 and Figure 6, the whole property of

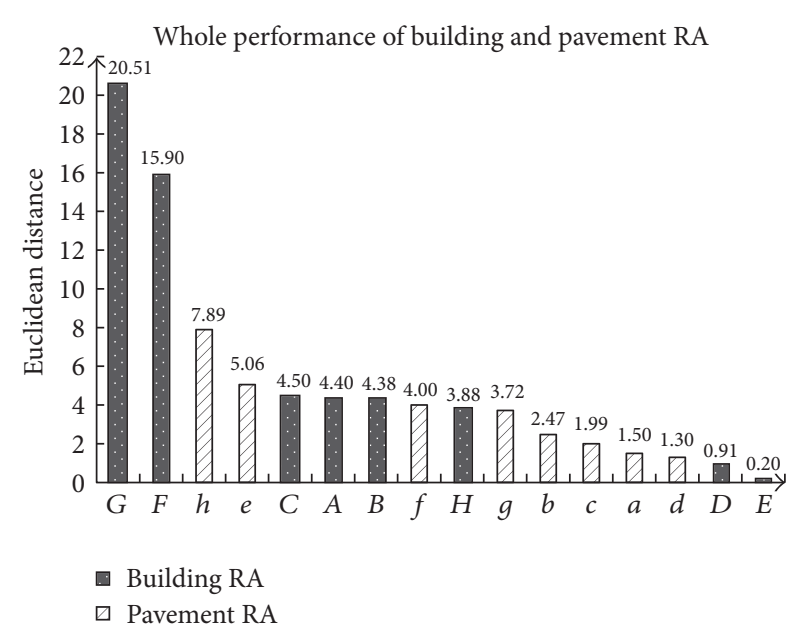

Figure 6: Whole property of RA.

RA with better single property may be poor, while the whole property of RA with poor property may be better.

From the size of Euclidean distance, it can be seen that the comprehensive properties of group $E$, group $D$, and group $d$ are the best, whereas group $G$ shows the worst results. The Euclidean distance of crushing value and water absorption is the largest, which shows a primary need to improve the property index of the RA.

The standard variances of the whole property Euclidean distances are 7.341 and 2.208, respectively, which shows that the property of building RA has great fluctuation, while pavement RA is more stable.

\section{Mahalanobis Distance Evaluation and Grading Methods of RA}

The analysis above indicates that the property evaluation of RA contains multiple indicators. Due to the instability of the properties of RA, its experimental data has a large variability. For different evaluation indices, different evaluation results are achieved. Since there exists certain dependence among properties of RA and Euclidean distance could not express the influence factors of the correlation among various properties of the samples, another index is proposed to solve this problem, named Mahalanobis distance.

5.1. Mahalanobis Distance Evaluation Model. Mahalanobis distance can discriminate the spatial distribution of a point relative to the total by calculating the distance to a certain point. Mahalanobis distance considers three parameters, 
TABLE 5: Euclidean distance of whole property of building and pavement RA.

\begin{tabular}{lccc}
\hline Building RA & Euclidean distance & Pavement RA & Euclidean distance \\
\hline$A$ & 4.397 & $a$ & 1.500 \\
$B$ & 4.375 & $b$ & 2.474 \\
$C$ & 4.502 & $c$ & 1.992 \\
$D$ & 0.905 & $d$ & 1.300 \\
$E$ & 0.200 & $e$ & 5.057 \\
$F$ & 15.900 & $f$ & 4.001 \\
$G$ & 20.511 & $g$ & 3.722 \\
$H$ & 3.880 & $h$ & 7.890 \\
\hline
\end{tabular}

mean value, variance, and covariance, which shows the translational invariance and invariance under nonsingular transformation. Mahalanobis distance can express the influencing factors of the correlation among different variables, and it is independent of the dimension of each characteristic parameter, and the judgement basis is according to the characteristic distribution condition of variables in the whole space $[18,19]$.

Suppose that there are two variables $G 1$ and $G 2$, which obey the state distribution, $x \in R_{p}$ is a new sample point, and the distance from $x$ to $G 1$ and $G 2$ is defined as follows:

$$
\begin{aligned}
& d\left(x, G_{1}\right)=\sqrt{\left(x-u^{(1)} \Sigma_{1}^{-1}\right)}\left(x-u^{(1)}\right), \\
& d\left(x, G_{2}\right)=\sqrt{\left(x-u^{(2)} \Sigma_{2}^{-1}\right)}\left(x-u^{(2)}\right),
\end{aligned}
$$

in which $\mu(1), \mu(2)$ are the mean vector of $G 1$ and $G 2 ; \Sigma_{1}, \Sigma_{2}$ are covariance matrix of set $G 1$ and $G 2$. rules:

Therefore it can be determined according to the following

$$
\begin{array}{ll}
d\left(x, G_{1}\right)<d\left(x, G_{2}\right), & x \in G_{1}, \\
d\left(x, G_{2}\right)<d\left(x, G_{1}\right), & x \in G_{2}, \\
d\left(x, G_{1}\right)=d\left(x, G_{2}\right), & \text { Judge. }
\end{array}
$$

The indices which can express the property of RA are defined as a vector $X(X 1, X 2, \ldots, X n)$, the mean vector of $X$ is $\mu(\mu 1, \mu 2, \ldots, \mu n)$, and the standard deviation vector is $\sigma$ $\left(\sigma_{1}, \sigma_{2}, \ldots, \sigma_{n}\right)$. The property standard is defined as vector $Y$ $(Y 1, Y 2, \ldots, Y n)$, so the vector $Y$ is degenerated into a point of the multidimensional space.

The global $G 1$ is defined by the vector $X$ and the global $G 2$ as $Y$; then the distance from a sample point of global $G 1$ to global $G 2$ is equal to the distance from a point of vector $X$ to vector $Y$ :

\section{$D(X, Y)$}

$$
=\sqrt{\frac{\left(Y_{1}-X_{1}\right)^{2}}{\sigma_{1}^{2}}+\frac{\left(Y_{2}-X_{2}\right)^{2}}{\sigma_{2}^{2}}+\cdots+\frac{\left(Y_{n}-X_{n}\right)^{2}}{\sigma_{n}^{2}}} .
$$

$D$ is a normalized distance of nonuniform distribution, and it can reflect the comprehensive index of RA property without the need to consider the dimension of each index and
TABLE 6: Grading methods of RA.

\begin{tabular}{lc}
\hline Grading of RA & Meet the conditions \\
\hline Grading 1 & $D\left(p_{1}^{\prime} p\right)<D\left(p_{2}^{\prime} p\right) \cup D\left(p_{1}^{\prime} p\right)<D\left(p_{3}^{\prime} p\right)$ \\
Grading 2 & $D\left(p_{2}^{\prime} p\right)<D\left(p_{1}^{\prime} p\right) \cup D\left(p_{2}^{\prime} p\right)<D\left(p_{3}^{\prime} p\right)$ \\
Grading 3 & $D\left(p_{3}^{\prime} p\right)<D\left(p_{1}^{\prime} p\right) \cup D\left(p_{3}^{\prime} p\right)<D\left(p_{2}^{\prime} p\right)$ \\
\hline
\end{tabular}

the choice of unit. Based on the characteristic distribution condition in the whole space, $D$ can express the effect of correlation among indices of RA. Therefore, $D$ can better describe the similarity between RA and the set, so as to provide a basis to determine the level of RA. The smaller the $D$ value, the better the property and vice versa.

\subsection{Mahalanobis Distance Calculation and Grading Method}

5.2.1. Mahalanobis Distance Calculation. Water absorption, crushing value, and adhesion are represented by $W, C$, and $N$, respectively. The evaluation index of RA comprehensive property can be considered as a three-dimensional vector $P(W, C, N)$, and assuming that the value of the three indicators is $P^{\prime}\left(W_{n}^{\prime}, C_{n}^{\prime}, N_{n}^{\prime}\right)$, we can calculate the distance $D$ between any RA and NA and then distinguish the whole property of RA.

$$
\begin{aligned}
D & \left(p_{n}^{\prime} p\right) \\
& =\sqrt{\frac{\left(W-W_{n}^{\prime}\right)^{2}}{\sigma_{W}^{2}}+\frac{\left(Q-Q_{n}^{\prime}\right)^{2}}{\sigma_{C}^{2}}+\cdots+\frac{\left(N-N_{n}^{\prime}\right)^{2}}{\sigma_{N}^{2}}},
\end{aligned}
$$

in which $W_{n}^{\prime}, Q_{n}^{\prime}, N_{n}^{\prime}$ are the water absorption, crushing value, and adhesion of different grades of NA. $W, Q, N$ are the average value of water absorption, crushing value, and adhesion of a certain RA. $\sigma_{W}^{2}, \sigma_{C}^{2}, \sigma_{N}^{2}$ are the standard deviation of water absorption, crushing value, and adhesion of a certain RA.

5.2.2. Grading Method of Mahalanobis Distance. When the $D\left(p_{1}^{\prime} p\right), D\left(p_{2}^{\prime} p\right), D\left(p_{3}^{\prime} p\right)$ represent, respectively, Mahalanobis distance grade 1 , grade 2 , and grade 3 , the RA can be graded by the methods of Table 6; therefore, Mahalanobis distance comprehensive evaluation method can be applied to evaluate some cases which are difficult to compare each other. 
TABLE 7: Mahalanobis distance between RA and natural aggregate.

\begin{tabular}{lcc}
\hline$D\left(p_{1}^{\prime} p\right)$ & $D\left(p_{2}^{\prime} p\right)$ & $D\left(p_{3}^{\prime} p\right)$ \\
\hline 27.531 & 11.624 & 13.751 \\
\hline
\end{tabular}

5.2.3. The Comprehensive Property Evaluation of RA. Based on the RA property test results, we can calculate the Mahalanobis Distance of RA, as is shown in Table 7.

As can be seen from Table $6, D\left(p_{2}^{\prime} p\right)<D\left(p_{3}^{\prime} p\right)<$ $D\left(p_{1}^{\prime} p\right)$, and therefore, this RA is nearest to the entirety of second class, and its level can be represented as two.

Compared with the other grading standard, Mahalanobis distance grading method is more intuitive, and it is convenient for operations without requiring a large number of property tests.

\section{Conclusions}

(1) RA is influenced by many factors, such as its source and crushing method. The numerical value of the property experiments shows obvious variability and instability. Compared to the property of pavement RA, building RA has a wider variability and lower stability.

(2) The distance method of comparison is not affected by the dimensions and it can be used to express the whole difference of various sample sets simply. The greater the distance value, the lower the similarity of the two samples.

(3) The calculation results of Euclidean distance show that the comprehensive property of the pavement RA $\left(S_{k}=2.208\right)$ is superior to that of building RA $\left(S_{k}=7.341\right)$. And for these two kinds of RA, the Euclidean distance of the property $\left(\rho_{k j}=0.52\right)$ and apparent relative density $\left(\rho_{k j}=1.87\right)$ are slightly different, whereas the change of water absorption $\left(\rho_{k j}=10.67\right)$ and crushing value $\left(\rho_{k j}=26.36\right)$ is quite remarkable. Thus, the water absorption rate and crushing value can approximately reflect the property differences of RA.

(4) Euclidean distance calculations show that there is a certain correlation among apparent density, water absorption rate, and crushing value. The lower the apparent density, the larger the water absorption rate and crushing value. However, the correlation for flakiness content is low, so the most important property indices for the RA are crushing value and water absorption, and at same time, the major improvement for these two property indices is needed as well.

(5) The Mahalanobis distance method can evaluate the comprehensive property of RA directly and provide grade evaluation guidance for RAs by considering the influence factors of the correlation among variables, such as parameters of mean, variance, and covariance.

\section{Additional Points}

Highlights. (i) It is clear that there has been a large variability about the individual property of recycled aggregate (RA), and it has been difficult to express the whole property in any single property parameter. (ii) A method is proposed to express the differences of the whole property of RAs using Euclidean distance method. (iii) A calculation model and evaluation method are provided for the whole property of RAs with Mahalanobis distance method.

\section{Conflicts of Interest}

The authors declare that they have no conflicts of interest.

\section{Acknowledgments}

This study was supported by the National Natural Science Foundation of China (Project 51578027).

\section{References}

[1] F. Xiao, B. Putman, and S. Amirkhanian, "Rheological characteristics investigation of high percentage RAP binders with WMA technology at various aging states," Construction and Building Materials, vol. 98, pp. 315-324, 2015.

[2] Y. C. Guo and K. W. Sun, "Consideration on new specifications of road materials based on properties of recycled ag-gregate," Journal of Chang'an University (Natural Science Edition), vol. 3, pp. 1671-8879, 2010.

[3] S. Nagataki, A. Gokce, T. Saeki, and M. Hisada, "Assessment of recycling process induced damage sensitivity of recycled concrete aggregates," Cement and Concrete Research, vol. 34, no. 6, pp. 965-971, 2004.

[4] Z. Q. Shi Jian guang, "Effects of different materials in the construction waste on the properties of concrete," Concrete, vol. 6, pp. 11-13, 2008.

[5] A. R. Chini, S.-S. Kuo, J. M. Armaghani, and J. P. Duxbury, “Test of recycled concrete aggregate in accelerated test track," Journal of Transportation Engineering, vol. 127, no. 6, pp. 486-492, 2001.

[6] V. W. Y. Tam and C. M. Tam, "A new approach in assessing cement mortar remains on recycled aggregate," Magazine of Concrete Research, vol. 59, no. 6, pp. 413-422, 2007.

[7] M. Etxeberria, A. R. Marí, and E. Vázquez, "Recycled aggregate concrete as structural material," Materials and Structures, vol. 40, no. 5, pp. 529-541, 2007.

[8] S. Y. Wang, P. H. Zhu, X. Wang, J. Zhou, and H. E. Xia, "Research on some key issues for applicat ion of recycled concrete," Concrete, vol. 4, pp. 39-41, 2008.

[9] G. R. Robinson Jr., W. D. Menzie, and H. Hyun, "Recycling of construction debris as aggregate in the Mid-Atlantic Region, USA," Resources, Conservation \& Recycling, vol. 42, no. 3, pp. 275-294, 2004.

[10] X. Yuezhou, The Numerical Simulation and Influence of Aggregate Gradation on the Compressive Strength of Recycled Aggregate Concrete, Xiamen University, 2007.

[11] Z. Zhang, K. Wang, H. Liu, and Z. Deng, "Key performance properties of asphalt mixtures with recycled concrete aggregate from low strength concrete," Construction and Building Materials, vol. 126, pp. 711-719, 2016.

[12] H. Sung Do, P. Hee Mun, and R. Suk keun, "A study on engineering characteristics of asphalt concrete using filler with recycled waste lime," Waste Management, vol. 28, no. 1, pp. 191199, 2008.

[13] Y. D. Wong, D. D. Sun, and D. Lai, "Value-added utilisation of recycled concrete in hot-mix asphalt," Journal of Waste Management, vol. 27, no. 2, pp. 294-301, 2007. 
[14] S. Wu, J. Zhong, J. Zhu, and D. Wang, "Influence of demolition waste used as recycled aggregate on performance of asphalt mixture," Road Materials and Pavement Design, vol. 14, no. 3, pp. 679-688, 2013.

[15] L. Huan, The Research for Recycled Concrete Aggregate and ITS Applied in Asphalt Pavement, Beijing University of Technology, Beijing, China, 2011.

[16] R. Hui, The Evaluation for Property of Recycled Coarse Concrete Aggregate Basing on Distance Method, Beijing University of Technology, Beijing, China, 2012.

[17] A. Stimilli, G. Ferrotti, A. Graziani, and F. Canestrari, "Performance evaluation of a cold-recycled mixture containing high percentage of reclaimed asphalt," Road Materials and Pavement Design, vol. 14, no. 1, pp. 149-161, 2013.

[18] K. L. Vasconcelos, A. Bhasin, and D. N. Little, "Influence of reduced production temperatures on the adhesive properties of aggregates and laboratory performance of fine aggregateasphalt mixtures," Road Materials and Pavement Design, vol. 11, no. 1, pp. 47-64, 2011.

[19] Z.-G. Zhao and F. Liu, "Application research of statistical monitoring index based on mahalanobis distance," Acta Automatica Sinica, vol. 34, no. 4, pp. 493-495, 2008. 

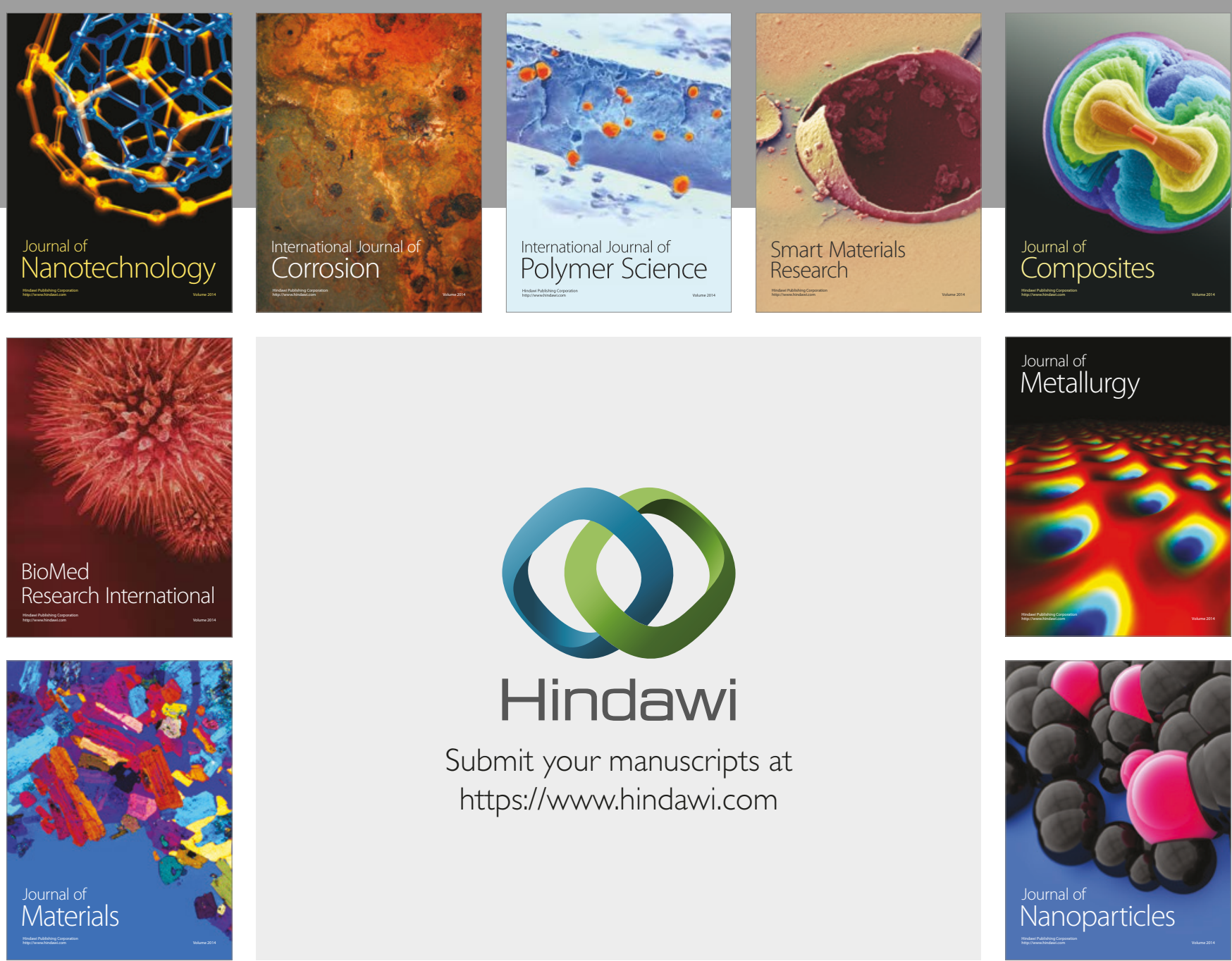

\section{Hindawi}

Submit your manuscripts at

https://www.hindawi.com
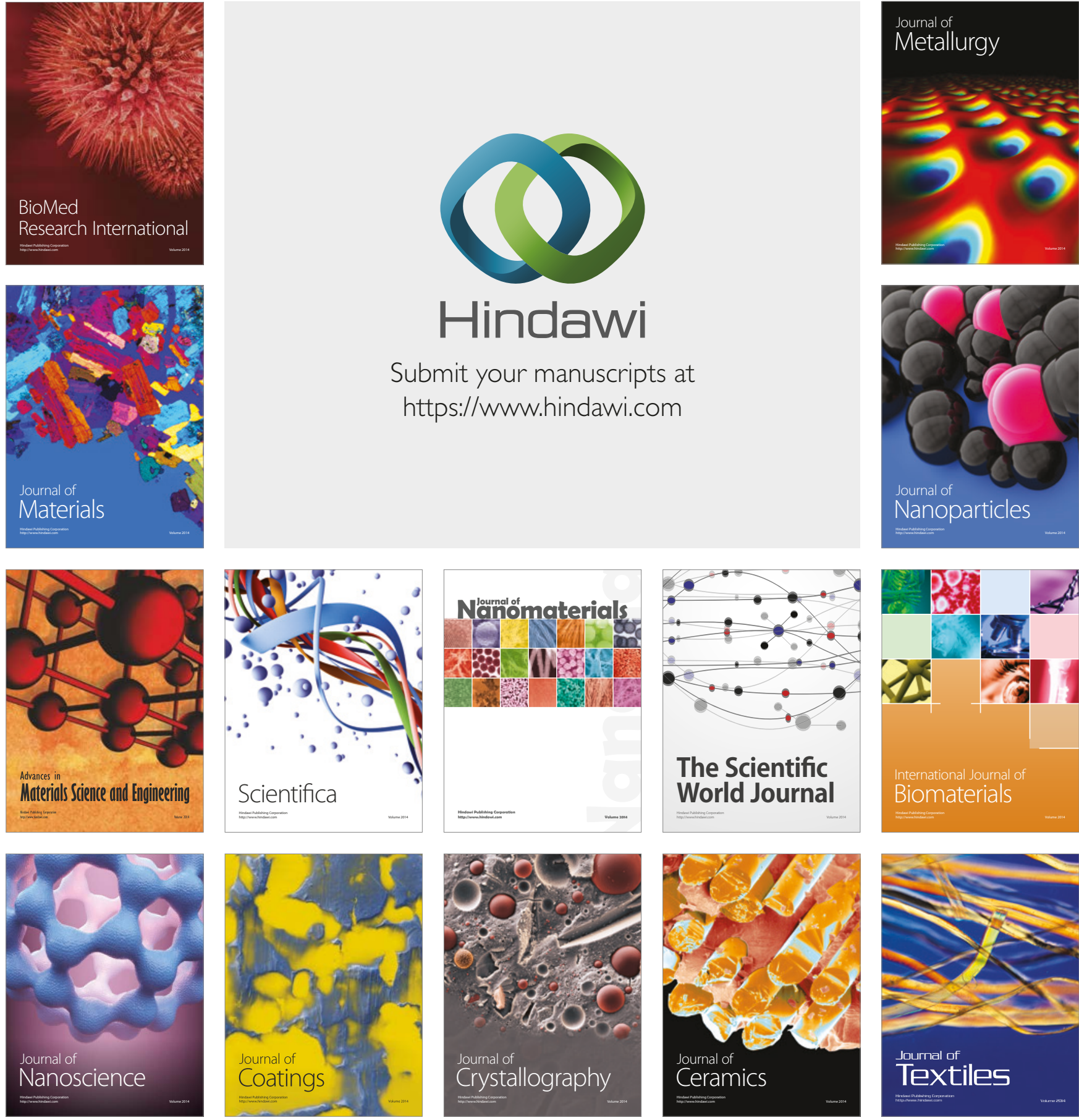

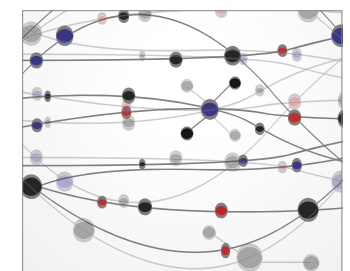

The Scientific World Journal
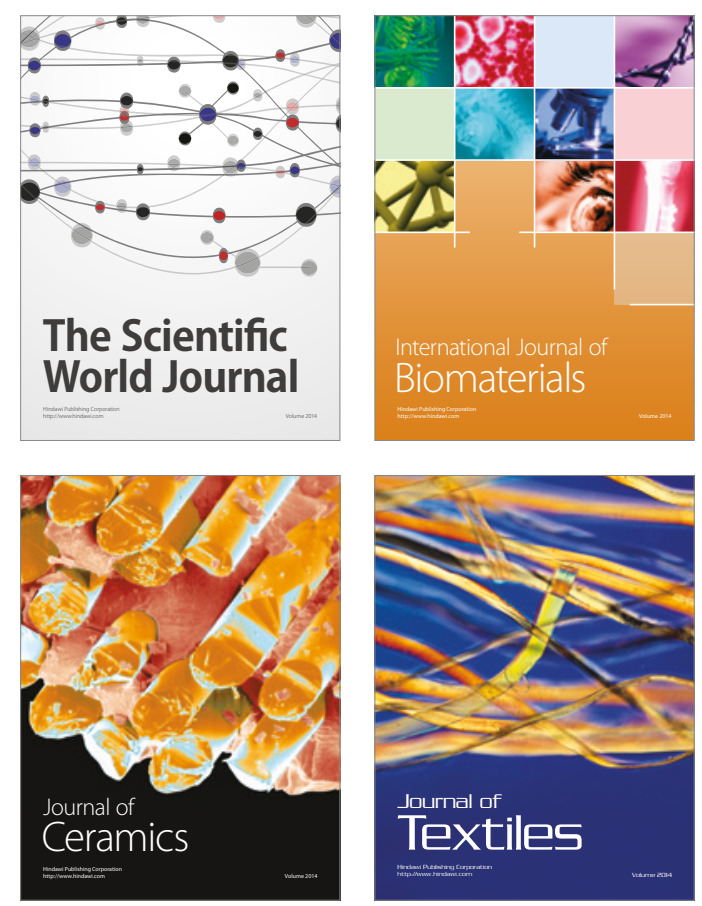